nguy cơ VAD-TLS cao hơn 1,5 lân nhóm bình thường $(p<0,05)$. Khuyến nghị cải thiện tình trạng vitamin A kết hợp với vi chất dinh dưỡng cho trẻ học đường để nâng cao tâm vóc và đảm bảo sự phát triển tốt nhất cho trẻ.

\section{TÀI LIÊU THAM KHẢO}

1. Stevens GA. Trends and mortality effects of vitamin A deficiency in children in 138 low-income and middle-income countries between 1991 and 2013: a pooled analysis of population-based surveys. Lancet Glob Health, 2015; 3(9): e528-36.

2. Viên Dinh Dưỡng. Đánh giá tình trang thiếu máu, thiếu một số vi chất dinh dưỡng của phụ nữ và trè em 6 - 59 tháng tai vùng thành thi, nông thôn và miền núi năm 2014 - 2015. Báo cáo đề tài nghiên cứu cấp Viện 2015.

3. Viện Dinh dưỡng, Tổng điều tra Dinh dưỡng 20009 - 2010. Nhà xuất bản Y học, 2010.

4. Yang $\mathbf{C}$, Chen $\mathbf{J}$, Liu $Z$ et al. Prevalence and influence factors of vitamin A deficiency of Chinese pregnant women. 2016. Nutr J. 2016; 15(1):12

5. Hoàng Văn Phượng, Lê Danh Tuyên, Trân Thúy $\mathbf{N g a}$, Nguyến Song Tú. Tình trang thiếu vitamin A và một số yếu tố liên quan ở trẻ 36-59 tháng tuổi nguy cơ suy dinh dưỡng thấp còi tai huyện đồng bằng sông Hồng, năm 2015. Tạp chí Ý hoc Việt Nam, 2017. Tập 458, (2): 216-220.

6. Bùi Thị Nhung, Lê Danh Tuyên, Cao Thị Thu Hương. Tình trạng thiếu vi chất dinh dưỡng của hoc sinh nguy cơ bi suy dinh dưỡng thấp còi và thấp còi tại huyện Nghĩa Đàn tỉnh Nghệ An năm 2013 - 2014. Táp chí Ý hoc dự phòng, 2017; 27: 32-37.

7. Laillou $\mathbf{A}$ et al. Micronutritent deficits are still public issues among women and young children in Vietnam. PlosOne, 2012; 7(4).

8. Viên Dinh dưỡng. Tông điều tra dinh dưỡng: mốt số kết quả chính 2019 - 2020. 2021

9. Le Nguyen BK, Le Thi $H$, Nguyen Do VA et al. Double burden of undernutrition and overnutrition in Vietnam in 2011: results of the SEANUTS study in 0.5-11-year-old children. $\mathrm{Br}$ J Nutr, 2013. 110 Suppl 3:S45-56.

\title{
HIỆU QUẢ TƯ VẤN GIẢM GÁNH NĂNG CHĂM SÓC BỆNH NHÂN ALZHEIMER TẠI BỆNH VIỆN LÃO KHOA TRUNG ƯƠNG NĂM 2020 - 2021
}

\section{TÓM TẮT}

Mục tiêu: Đánh giá hiệu quả tư vấn giảm gánh năng chăm sóc bệnh nhân Alzheimer và một số yếu tố liên quan. Đối tượng và phương pháp: Nghiên cứu can thiệp tư vấn giảm gánh nặng trên 52 người chăm sóc bênh nhân Alzheimer tai Bênh viên Lão Khoa Trung ương từ năm 2020 đển năm 2021. Đánh giá hiêu quả bằng thang điểm ZBI trước và 2 tuần sau tư vấn. Kết quả: Sau can thiệp gánh nặng chăm sóc giảm từ 43,7 điểm xuống còn 28,7 điểm theo ZBI. NCS lao động toàn thời gian có tỷ lệ cải thiện ZBI thấp hơn nhiêu so với nhóm cỏn lai $(p<0,05)$. Sư cải thiên ZBI cao hơn có ý nghĩa thống kê ở nhóm NCS có thời gian chăm sóc trong ngày kéo dài và bênh nhân SSTT giai đoạn vừa và nặng so với nhóm còn laai. Kết luận: Tư vấn giúp NCS giảm gánh nă̆ng chẳm sóc có ý nghĩa thống kê và liên quan đến đặc điểm giai đoạn bệnh, thời gian chăm sóc người bệnh và nghề nghiệp của NCS.

Tư khóa: Alzheimer, gánh nặng chăm sóc, thang điểm Zarit.

\section{SUMMARY}

\section{EFFECTIVE CONSULTING TO REDUCE THE}

\author{
${ }^{1}$ Bệnh viện Lão khoa Trung ương \\ ${ }^{2}$ Trường Đại họ Thăng Long \\ Chịu trách nhiệm chính: Nguyễn Ngọc Ánh \\ Email: ngocanh.nig@gmail.com \\ Ngày nhận bài: 5.5.2021 \\ Ngày phản biên khoa học: 22.6.2021 \\ Ngày duyệt bài: 2.7.2021
}

\section{Nguyễn Ngọc Ánh', Đỗ Thị Khánh Hỳ̃1,2 CAREGIVER BURDEN OF PATIENTS WITH ALZHEIMER'S DISEASE AT NATIONAL GERIATRIC HOSPITAL FROM 2020 TO 2021}

Objective: Effective evaluation consulting to reduce the burden of caring with Alzheimer's patients and related factors. Methods: An interventional study on 52 caregivers of Alzheimer's patients at National Geriatric Hospital from 2020 to 2021. Evaluation of effectiveness by ZBI scale before and 2 weeks after counseling. Results: After counseling, the burden of care decreased from 43.7 to 28.7 points according to ZBI $(p<0.05)$. The full-time jobs caregiver had a rate of improvement in ZBI lower than the other groups $(p<0.05)$. The improvement in ZBI was statistically significant in caregivers with prolonged day-to-day care and in patients with moderate and severe dementia conclusions: Counseling for the caregivers have reduced the burden significantly, that is related to the disease stage, patient care time per day or the occupation of caregivers.

Key words: Alzheimer, burden of caregiver, Zarit Burden Interview

\section{I. Đă̆T VẤN ĐỀ}

Ngày nay, tuổi tho tăng lên kéo theo sự gia tăng các bệnh lý thoái hóa, trong đó có các rối loạn sa sút trí tuệ. Trên thế giới ít nhất 50 triệu người đang sống chung với bệnh Alzheimer hoặc các chứng sa sút trí tuê khác và dự kiến có thề vượt quá 152 triệu người mắt vào năm 2050 [1]. Người bệnh Alzheimer đa số được chăm sóc tại nhà, người chăm sóc thường không được đào 
tạo, thiếu hiểu biết về bệnh, không có kỹ năng giải quyết các vấn đề liên quan đến rối loạn hành vi của người bệnh, điêuu này tạo nên gánh nặng lớn cho các thành viên trong gia đình. Gánh nặng có thể dẫn đến chất lượng chăm sóc kém, bỏ mặc bệnh nhân, thậm chí lạm dụng và trở thành nguyển nhân cân phải gửi người bệnh Alzheimer vào nhà dương lão[1]. Bên cạnh người bệnh, những người chăm sóc cũng cân được giúp đõ. Việc tư vấn giảm gánh nặng cho người chăm sóc tập trung chủ yếu vào việc cung cấp các kiến thức liên quan đến bệnh Alzheimer, hướng dẫn rèn luyện những kỹ năng chăm sóc cũng như cách cách giải quyết các vấn đề liên quan đến hành vi của người bệnh. Những hỗ trợ cảm xúc và thư giãn sẽ giúp cho người chăm sóc giảm căng thẳng. Bệnh viện Lão Khoa Trung ương là đơn vị đi đầu xây dựng chương trình quản lý người bệnh Alzheimer cũng như tư vấn giảm gánh nặng cho người chăm sóc. Tuy nhiên hiệu quả can thiệp tư vấn chưa được quan tâm đánh giá. Chúng tôi thực hiện nghiên cứu này với mục tiêu: Đánh giá hiệu quả tư vân giảm gánh nặng cho người chăm sóc bệnh nhân Alzheimer tại Bệnh viên Lão khoa Trung ương năm 2020 - 2021 và một số yếu tố liên quan.

\section{II. ĐỐI TƯƠNG VÀ PHƯƠ'NG PHÁP NGHIÊN CỨU}

2.1. Đối tượng nghiên cứu. Nghiên cứu thực hiện trên 52 trường hợp người chăm sóc (NCS) bệnh nhân đã được chẩn đoán xác định Alzheimer theo tiêu chuẩn DSM IV-TR của Hội tâm thần học Hoa Kỳ nằm điêu trị nội trú tại khoa Thần kinh và Bệnh Alzheimer Bệnh viện Lão khoa Trung ương.

2.2. Phương pháp nghiên cứu. Nghiên cứu can thiệp lấy mẫu thuận tiện

Các biến số và chỉ số thu thập theo mẫu bệnh án nghiên cứu, bao gồm:

+ Thông tin chung của người bệnh và người chăm sóc

+ Đánh giá mức độ nặng của các triệu chứng, giai đoạn sa sút trí tuệ và các dấu hiệu rối loạn tâm thẩn và hành vi (BPSD)

+ Đánh giá gánh nặng chăm sóc của người chăm sóc bằng sử dụng thang điểm Zarit (Zarit Burden Interview-ZBI) (Bảng 1) với tổng điểm từ 0 đến 88 điểm với các mức độ: từ 0 đến 20 điểm: không có hoăc có gánh năng nhe; 21 đến 40 điểm: gánh nặng mức độ trung bình; 41 đến 60 điểm: gánh nặng nghiêm trọng; 61 đến 88 điểm: gánh nặng rất nghiêm trọng.

\section{Bảng 1. Thang điểm Zazit}

Hướng dẫn đối với người chăm sóc: Những câu hỏi dưới đây phản ánh mức độ cảm nhận khi phải chăm sóc người bệnh. Sau mỗi vấn đề, hãy khoanh tròn vào câu trả lời mà ông/bà cho là đúng nhất (theo mức độ cảm nhận)

\begin{tabular}{|c|c|c|c|c|c|}
\hline \multirow[b]{2}{*}{ Câu hỏi } & \multicolumn{5}{|c|}{ TRÁ LỜI } \\
\hline & $\begin{array}{l}\text { Không } \\
\text { bao giờ }\end{array}$ & $\begin{array}{c}\text { Hiếm } \\
\text { khi }\end{array}$ & $\begin{array}{l}\text { Thinh } \\
\text { thoảng }\end{array}$ & $\begin{array}{c}\begin{array}{c}\text { Khá thường } \\
\text { xuyên }\end{array} \\
\end{array}$ & $\begin{array}{l}\text { Luôn } \\
\text { luôn }\end{array}$ \\
\hline $\begin{array}{l}\text { 1. Ông/bà có cảm thấy người bệnh đòi hỏi phục vụ } \\
\text { nhiều hơn nhu cầu không? }\end{array}$ & 0 & 1 & 2 & 3 & 4 \\
\hline $\begin{array}{l}\text { 2. Có phải ông/bà cảm thấy như vậy vì mình phải } \\
\text { dành hết thời gian cho người bệnh mà không còn } \\
\text { thời gian dành cho bản thân không? }\end{array}$ & 0 & 1 & 2 & 3 & 4 \\
\hline $\begin{array}{l}\text { 3. Ông/bà có cảm thây căng thẳng giữa việc chăm } \\
\text { sóc người bệnh và cố gắng thực hiện nghĩa vụ đối } \\
\text { với gia đình hoặc công việc không? }\end{array}$ & 0 & 1 & 2 & 3 & 4 \\
\hline $\begin{array}{l}\text { 4. Ông/bà có cảm thây bị rắc rôi vì hành vi của } \\
\text { người bệnh không? }\end{array}$ & 0 & 1 & 2 & 3 & 4 \\
\hline $\begin{array}{l}\text { 5. Ông/bà có cảm thấy bực bội khi phải ở bên cạnh } \\
\text { người bênh không? }\end{array}$ & 0 & 1 & 2 & 3 & 4 \\
\hline $\begin{array}{l}\text { 6. Ông/bà có cảm thấy người bệnh làm ảnh hưởng } \\
\text { xấu đến mối quan hệ hiện nay của ông/bà với các } \\
\text { thành viên khác trong gia đình hoặc với bạn bè không? }\end{array}$ & 0 & 1 & 2 & 3 & 4 \\
\hline $\begin{array}{l}\text { 7. Ông/bà có cảm thấy lo lắng về những nguy cơ } \\
\text { sẽ xảy ra đối với người bênh không? }\end{array}$ & 0 & 1 & 2 & 3 & 4 \\
\hline $\begin{array}{l}\text { 8. Ông/bà có cảm thây người bệnh bị phụ thuộc } \\
\text { vào ông/bà không? }\end{array}$ & 0 & 1 & 2 & 3 & 4 \\
\hline
\end{tabular}




\begin{tabular}{|c|c|c|c|c|c|}
\hline $\begin{array}{l}\text { 9. Ông/bà có cảm thây căng thẳng khi phải ở bên } \\
\text { cạnh người bệnh không ? }\end{array}$ & 0 & 1 & 2 & 3 & 4 \\
\hline $\begin{array}{l}\text { 10. Ông/bà có cảm thấy sức khỏe của mình bị giảm } \\
\text { sút vì phải chăm sóc người bệnh không? }\end{array}$ & 0 & 1 & 2 & 3 & 4 \\
\hline $\begin{array}{l}\text { 11. Ông/bà có cảm thây bị giảm bớt cuộc sống } \\
\text { riêng tư của mình vì phải chăm sóc người bệnh không? }\end{array}$ & 0 & 1 & 2 & 3 & 4 \\
\hline $\begin{array}{l}\text { 12. Ông/bà có cảm thấy cuộc sống xã hội của mình bị } \\
\text { giảm bớt vì phải chăm sóc người bệnh không? }\end{array}$ & 0 & 1 & 2 & 3 & 4 \\
\hline $\begin{array}{l}\text { 13. Ông/bà có cảm thấy bất tiện khi có nhiêu bạn } \\
\text { bè đến thăm người bệnh không? }\end{array}$ & 0 & 1 & 2 & 3 & 4 \\
\hline $\begin{array}{l}\text { 14. Ông/bà có cảm thấy dường như người bệnh } \\
\text { trông đợi ông/bà chăm sóc nêu như người bệnh chì } \\
\text { có thể nhờ một người chăm sóc duy nhất? }\end{array}$ & 0 & 1 & 2 & 3 & 4 \\
\hline $\begin{array}{l}\text { 15. Ông/bà có cảm thấy mình không có đủ tiên để } \\
\text { chăm sóc người bệnh thêm vào những khoản chi } \\
\text { tiêu của mình không? }\end{array}$ & 0 & 1 & 2 & 3 & 4 \\
\hline $\begin{array}{l}\text { 16. Ông/bà có cảm thấy mình không thể chăm sóc } \\
\text { người bệnh lâu dài hơn nữa không? }\end{array}$ & 0 & 1 & 2 & 3 & 4 \\
\hline $\begin{array}{l}\text { 17. Ông/bà có cảm thây mất kiểm soát cuộc sống của } \\
\text { mình kể từ khi người bệnh bị ốm không? }\end{array}$ & 0 & 1 & 2 & 3 & 4 \\
\hline $\begin{array}{l}\text { 18. Ông/bà có mong muốn để người khác chăm } \\
\text { sóc người bệnh thay cho mình không? }\end{array}$ & 0 & 1 & 2 & 3 & 4 \\
\hline $\begin{array}{l}\text { 19. Ông/bà có cảm thấy không chắc chắn về } \\
\text { những việc mình đã làm cho người bệnh không? }\end{array}$ & 0 & 1 & 2 & 3 & 4 \\
\hline $\begin{array}{l}\text { 20. Ông/bà có cảm thấy cần phải làm nhiêu việc } \\
\text { hơn nữa cho người bệnh không? }\end{array}$ & 0 & 1 & 2 & 3 & 4 \\
\hline $\begin{array}{l}\text { 21. Ông/bà có cảm thấy mình có thể chăm sóc } \\
\text { người bệnh tốt hơn nữa không? }\end{array}$ & 0 & 1 & 2 & 3 & 4 \\
\hline $\begin{array}{l}\text { 22. Nói chung, ông/bà cảm thấy gánh nặng chăm } \\
\text { sóc người bệnh như thế nào? }\end{array}$ & 0 & 1 & 2 & 3 & 4 \\
\hline Tổng điểm & & & & & \\
\hline
\end{tabular}

+ Tư vấn giảm gánh nặng chăm sóc bao gồm:

- Cung cấp kiến thức về bệnh SSTT do Alzheimer

- Hướng dẫn các kỹ năng giải quyết vấn đề/Hành vi của người bệnh

- Hướng dẫn kiểm soát tâm trạng của NCS

2.3. Thời gian và địa điểm nghiên cứu. Nghiên cứu được thực hiện từ tháng 12/2020 đến tháng 5/2021 tại bệnh viện Lão khoa TW.

2.4. Thu thập và xử lý số liệu. Thu thập số liệu theo mẫu bệnh án nghiên cứu. Nhập và lưu trữ số liệu trên phần mềm Epidata 3.1; xử lý số liệu bằng các phương pháp thống kê y học trên phần mềm Stata 12.0.
2.5. Đạo đức nghiên cứu. Nghiên cứu được thực hiện với sự đồng ý tham gia của người chăm sóc và người bệnh, Tất cả các thông tin cá nhân và bệnh tật được giữ bí mật và chỉ phục vụ mục đích nghiên cứu. Người chăm sóc có quyền dừng tham gia hoặc rút khỏi nghiên cứu bất cứ lúc nào.

\section{KẾT QUẢ NGHIÊN CứU}

Nghiên cứu thực hiện trên 52 trường hợp người chăm sóc bệnh nhân Alzheimer có độ tuổi trung bình $57,4 \pm 14,2$, chủ yếu NCS là nữ $(65,4 \%)$ thu được một số kết quả như sau:

Bảng 2. Chỉ số gánh nặng chăm sóc ZBI trước tư vân và sau tư vân

\begin{tabular}{|c|c|c|c|c|c|}
\hline \multirow{2}{*}{ Phân loại mức độ } & \multicolumn{2}{|c|}{ Trước tư vấn } & \multicolumn{2}{|c|}{ Sau tư vấn } & \multirow{2}{*}{ p } \\
\cline { 2 - 5 } & $\mathbf{n}$ & $\mathbf{\%}$ & $\mathbf{n}$ & $\mathbf{\%}$ & \\
\hline Không hoặc gánh nặng nhẹ & 7 & 13,5 & 17 & 32,7 & \multirow{2}{*}{0,0000} \\
\hline Gánh nặng trung bình & 15 & 28,8 & 23 & 44,2 & \\
\hline Gánh nặng nghiêm trọng & 23 & 44,2 & 12 & 23,1 & \\
\hline
\end{tabular}




\begin{tabular}{|c|c|c|c|c|c|}
\hline Gánh nặng rất nghiêm trọng & 7 & 13,5 & 0 & 0 & \\
\hline ZBI Trung bình \pm SD & & & & & 0,0000 \\
\hline Mức cải thiên ZBI \pm SD & \multicolumn{4}{|c|}{$13,9 \pm 11,1$} & \\
\hline
\end{tabular}

Sau tư vấn gánh nặng chăm sóc giảm từ 43,7 điểm xuống còn 28,7 điểm theo ZBI. Ngoài ra mức độ gánh nặng nghiêm trọng và rất nghiêm trọng cũng giảm sau tư vấn, lần lượt từ $44,2 \%$ và $13,5 \%$ giảm còn $23,1 \%$ và $0 \%$. Sự khác biệt này có ý nghĩa thống kê với $p<0,001$.

Bảng 3. Một số yếu tố về NCS liên quan đến hiệu quả tư vấn giảm gánh nặng chăm sóc

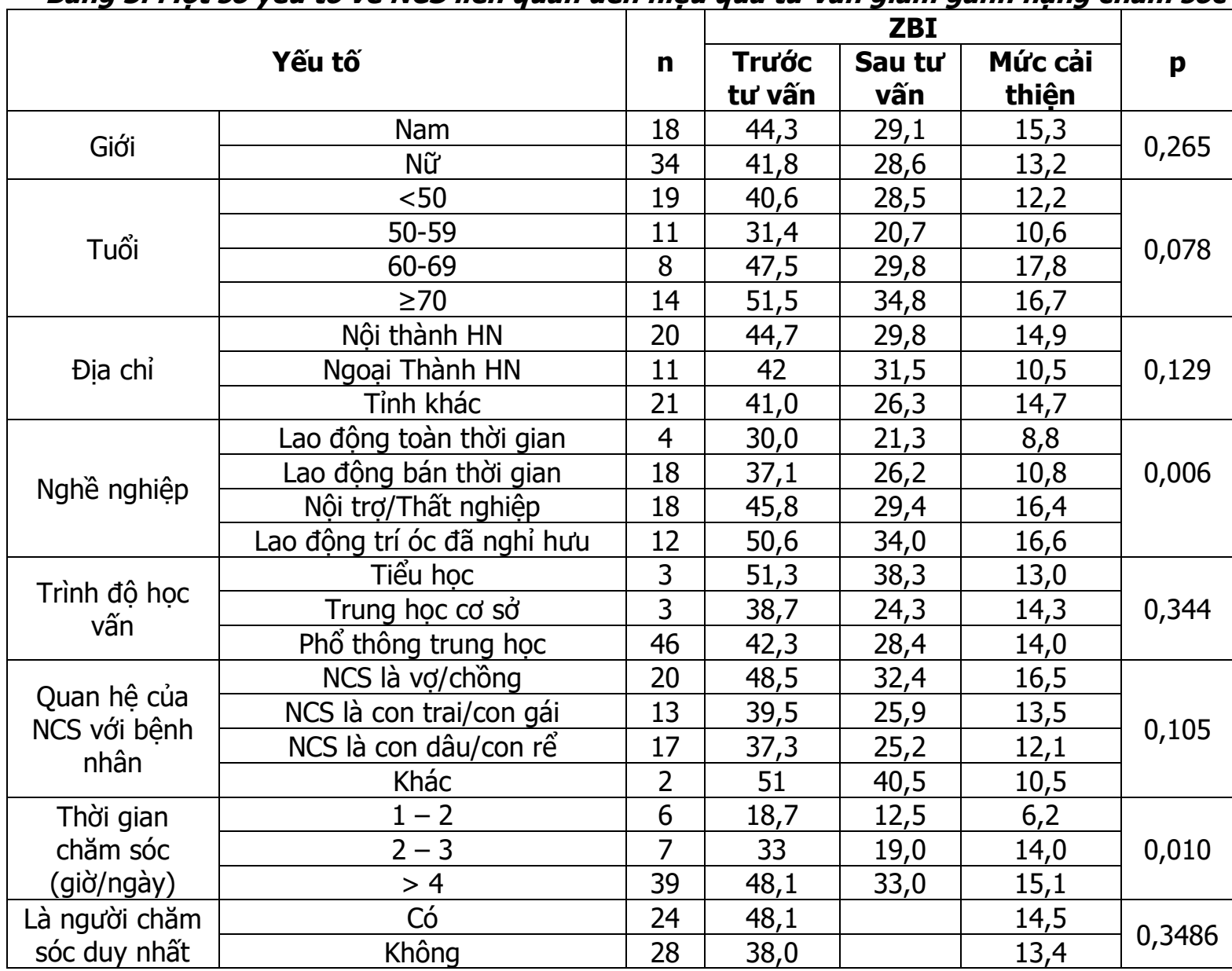

NCS lao động toàn thời gian có tỷ lệ cải thiện ZBI thấp hơn nhiều so với nhóm cỏn lại $(p<0,05)$. Nhóm thời gian chăm sóc trong ngày càng dài, khả năng cải thiện ZBI sau tư vấn càng cao $(p<0,05)$.

Bảng 4. Một số yếu tố của người bệnh liên quan đến hiệu quả tư vấn gánh nặng chăm sóc

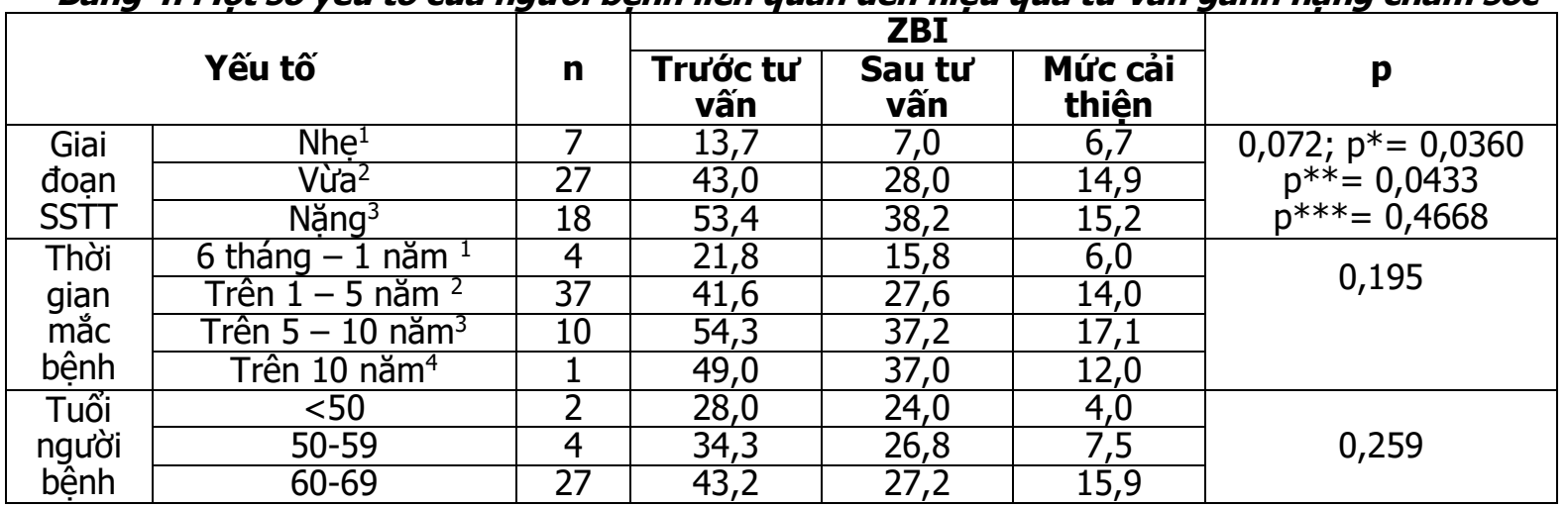


VIETNAM MEDICAL JOURNAL N01 - JULY- 2021

\begin{tabular}{|c|c|c|c|c|c|c|}
\hline & $\geq 70$ & 19 & 45,3 & 31,8 & 13,5 & \\
\hline \multirow{2}{*}{ Giới } & Nam & 20 & 42,6 & 27,4 & 15,3 & \multirow{2}{*}{0,2519} \\
\cline { 2 - 6 } & Nữ & 32 & 42,7 & 29,6 & 13,1 & \\
\hline
\end{tabular}

p*: sự khác biệt đặc điểm ${ }^{1}$ và ${ }^{2}$

$\mathrm{p}^{* *}$ : sự khác biệt đặc điểm ${ }^{1}$ và ${ }^{3}$

p*: sự khác biệt đặc điểm ${ }^{2}$ và ${ }^{3}$

Sư cải thiên ZBi sau tư vấn hiệu quả tốt hơn ở nhóm SSTT giai đoan vừa và nắng so với giai đoạn nhe $(p<0,05)$. Không có sự khác biệt có ý nghĩa thống kê về hiệu quả tư vấn theo tuổi, giới và thời gian mắc bệnh.

\section{BÀN LUÂ̂N}

Gánh nặng chăm sóc được hiểu là "những căng thẳng có thể được những người chăm sóc cho một người khác trải nghiệm, thường là một thành viên trong gia đình bị mắc một bệnh nào đó". Nghiên cứu của chúng tôi thực hiện trên 52 trường hợp người chăm sóc (NCS) bệnh nhân Alzheimer cho thấy gánh nặng chăm sóc trung bình tính theo thang điểm Zarit (ZBI) trước tư vấn là $42,7 \pm 17,1$ điểm, trong đó có $86,5 \%$ trường hợp gánh nặng trung bình trở lên, tương đương trên 21 điểm. Tỷ lệ gánh nặng nghiêm trọng và rất nghiêm trọng lần lượt là $44,2 \%$ và $13,5 \%$. Chúng tôi đánh giá lại sau tư vấn hai tuần, gánh nặng chăm sóc giảm $15,8 \%$, tương đương giảm trung bình 13,9 điểm. Ngoài ra, không có trường hợp nào gánh nặng mức độ rất nghiêm trọng và chỉ có $23,1 \%$ gánh nặng nghiêm trọng. Sự khác biệt này có ý nghĩa thổng kê với $p<0,05$. Kết quả này tương tự nhiều nghiên cứu khác trên thế giới cho thây việc tư vấn can thiệp có hiệu quả cao làm giảm gánh nặng và nâng cao chất lượng sống cho người chăm sóc. Nghiên cứu của Manuel năm 2009 đánh giá hiệu quả chương trình tư vấn cho NCS bệnh nhân Alzheimer giúp giảm 17,3 điểm gánh nặng theo ZBI và khác biệt này có ý nghĩa so với nhóm chứng [2]. Một nghiên cứu tổng quan hệ thống năm 2013 của Camil và cộng sự dựa trên 8 thử nghiệm lâm sàng cũng cho thây bằng chứng về hiệu quả chương trình giáo dục và hổ trợ có tác động tích cực đến việc giảm gánh nặng của NCS so với dịch vụ chăm sóc tiêu chuẩn, và thậm chí hiệu quả của nó còn kéo dài đến 6 tháng sau tư vấn. Do đó, việc đưa các chương trình này vào các cơ sở chăm sóc người cao tuổi mắc các bênh lý sa sút trí tuê là cần thiết và có hiệu quả [3]. Một chương trình can thiệp tư vấn đa dạng kèm theo giáo dục tâm lý dưởng như dẫn đến một loạt các thay đổi trong cách NCS giải quyết các vẩn đề liên quan đến chăm sóc người bệnh Alzheimer, giúp họ tiếp cận và đối phó dễ dàng hơn với các tình huống phát sinh.

Tìm hiểu một sỗ yễu tố liên quan đến hiệu quả tư vấn giảm gánh nặng của NCS, chúng tôi nhận thấy NCS lao động toàn thời gian có tỷ lệ cải thiện ZBI thấp hơnn nhiều so với nhóm cỏn lại $(p<0,05)$ bao gồm NCS làm việc bán thời gian, NCS ở nhà nội trở hoăc đã nghỉ hưu. Điều này có thể liên quan đến thời gian dành cho chăm sóc người bệnh có liên quan chặt chẽ đên gánh nặng chăm sóc. Ngoài thời gian chăm bệnh nhân, NCS còn phải đảm bảo hoàn thành công việc toàn thời gian của mình, gánh nặng chăm sóc của họ lớn hơn cũng như đáp ứng với chương trình tư vấn thấp hơn. Ngược lại, khi xét đến yếu tố thời gian chăm sóc/ngày cho thấy nhóm NCS phải dành trên 4 giờ/ngày cho việc chăm sóc bệnh nhân dường như tỷ lệ giảm gánh nặng ZBI cao hơn nhóm còn lại $(p<0,05)$. Điều này có thể do điểm ZBI trước tư vấn của nhóm này đã cao hơn đáng kể so với nhóm còn lại, nên đáp ứng với chương trình tư vấn cũng có xu hướng cao hơn. Tuy nhiên do cõ̃ mẫu khác biệt lớn giữa các nhóm trên cần các nghiên cứu khác với cỡ mẫu lớn hơn tìm hiểu ảnh hưởng của nghề nghiệp và thời gian chăm sóc người bệnh đên hiẹu quả giảm gánh nặng chăm sóc. Khi đánh giá các yếu tố liên quan của người bệnh, sự cải thiện ZBI sau tư vấn có xu hướng tốt hơn ở nhóm SSTT giai đoạn vừa và nặng so với giai đoạn nhẹ $(p<0,05)$. Tương tự như các yếu tố của NCS phân tích ở trên, giai đoạn SSTT vừa và nặng với sự xuất hiện nhiều hơn các triệu chứng rối loạn tẩm thần và hành vi, gánh nặng của NCS cũng lớn hơn, đòi hỏi thời gian chăm sóc nhiêu hơn và nhu câu về những kiến thức và kỹ năng ứng phó cao hơn. Viêc được tư vấn hướng dẫn và xử trí trước các tình huống rối loạn của người bênh đem lại kết quả rõ rệt hơn so với giai đoạn nhẹ khi các triệu chứng chưa quá nặng và mức độ ảnh hưởng đến NCS chưa nhiều. Nhiều nghiên cứu trong nước và trên thế giới đã cho thây gánh nặng chăm sóc có liên quan tương quan thuận với thời gian phát hiện bệnh của bệnh nhân, triệu chứng loạn thần và rối loạn hành vi của bệnh nhân, tuổi người chăm sóc, thời gian chăm sóc, là người chăm sóc duy nhất [4] [6]. Tuy nhiên không có sự khác biệt có ý nghĩa thống kê về hiệu quả tư vấn giảm gánh nặng chăm sóc liên quan đến các yếu tố kể trên. Kết 
quả này cũng tương đồng với các nghiên cứu khác trên thế giới cho thấy ít có bằng chứng về mă̆t thống kê liên quan đến các đăc điểm của người bênh hay người chăm sóc có những đáp ứng tốt hơn hay kém hơn với chương trình tư vấn [3].

\section{KẾT LUẬN}

Sau tư vấn, gánh nặng chăm sóc giảm từ 43,7 điểm xuống còn 28,7 điểm theo ZBI $(p<0,05)$. NCS lao động toàn thời gian có tỷ lệ cải thiện ZBI thấp hớn so với nhóm còn lại $(p<0,05)$. Sự cải thiện ZBI có xu hướng cao hớn có ý nghĩa thống kể ở nhóm NCS có thời gian chăm sóc trong ngày kéo dài và bệnh nhân SSTT giai đoạn vừa và nặng so với nhóm còn lại.

\section{TÀI LIẸU THAM KHẢO}

1. World Alzheimer Report 2018 - The state of the art of dementia research: New frontiers. NEW
FRONTIERS, 48.

2. Martín-Carrasco M., Martín M.F., Valero C.P. và công sứ. (2009). Effectiveness of a psychoeducational intervention program in the reduction of caregiver burden in alzheimer's disease patients' caregivers. Int J Geriat Psychiatry, 24(5), 489-499.

3. Marim C.M., Silva V., Taminato $M$. và cộng sự. (2013). Effectiveness of educational programs on reducing the burden of caregivers of elderly individuals with dementia: a systematic review. Rev Latino-Am Enfermagem, 21(spe), 267-275.

4. Nguyến Thanh Bình, Nguyễn Trọng Hưng, và Phạm Thắng (2016). Gánh nặng chăm sóc bệnh nhấn Alzheimer giai đoạn cuối và các yếu tố liên quan. Tạp chí nghiên cứu y học, 100(2), 148-155.

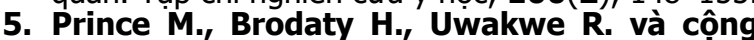
sư. (2012). Strain and its correlates among carers of people with dementia in low-income and middle-income countries. A 10/66 Dementia Research Group population-based survey. Int J Geriatr Psychiatry, 27(7), 670-682.

\section{NGHIÊN CỨU ĐĂC ĐIỂM LÂM SÀNG, CÂN LÂM SÀNG CỦA BÊ̂NH NHÂN VÕ̃ BÀNG QUANG DO CHẨN THƯƠNG ĐƯỢC ĐIỀU TRI BẰNG PHẪU THUÂ̂T NộI SOI TẠI BỆNH VIỆN VIỆT ĐỨC}

\section{TÓM TẮT}

Mục tiêu: Nghiên cứu đặc điểm lâm sàng, cận lâm sàng của bệnh nhân vỡ bàng qua do chấn thươning tại bệnh viện Việt Đức từ tháng 1/2014 - 9/2020. Phướng pháp nghiên cứu: nghiên cứu mô tả cắt ngang kết hợp hồi cứu và tiến cứu trên 67 bệnh nhân vỡ bàng quang được điều trị tại bệnh viện Việt Đức. Kết quả: Tuổi trung bình của bệnh nhẩn là $34,5 \pm$ 12,8 tuổi; Bệnh nhân nam chiếm $82,1 \%$, nữ chiếm $17,9 \%$. Nguyên nhân do tai nạn giao thông chiếm $86,6 \%$, tai nạn lao động 13,4\%; Thời gian trung bình từ khi bệnh nhân bị tai nạn đến khi vào viện là 4,08 \pm 1,34 giờ; Thời gian trung bình từ khi bệnh nhân nhập viện đến khi đước chẩn đoán là 3,02 $\pm 1,14$ giờ; Sốc chấn thương chiếm $37,3 \%$; Kết quả chụp X quang: Võ xương chậu $11,9 \%$, có hơi trong ổ bụng $11,9 \%$, có dịch ổ bụng 4,5\%; Kết quả chụp cắt lớp vi tính: Tổn thương thành bàng quang $85,1 \%$, thoát thuốc vào ổ bưng 43,3\%, hình ảnh vỡ xương chậu 40,3\%;Tạng tổn thương phối hợp: tốn thương gan chiếm $6 \%$, thận $1,5 \%$, lách 1,5\%, đại tràng 9,0\%, Xương chậu 40,3\%.

\footnotetext{
${ }^{1}$ Trường Cao đẳng Y tế Hà Nội

²Bệnh viện Đa khoa Xanh pôn

Chịu trách nhiệm chính: Nguyễn Minh An

Email: Dr_minhan413@yahoo.com

Ngày nhận bài: 4.5.2021

Ngày phản biện khoa học: 23.6.2021

Ngày duyệt bài: 5.7.2021
}

\section{Nguyễn Minh An ${ }^{1}$, Nguyễn Văn Đức ${ }^{2}$}

Kết luận: Chấn thương võ bàng quang thường gặp ở độ tuổi lao động, nguyên nhân do tai nạn giao thông chiếm đa số với tỷ lệ sốc chấn thương là $37,3 \%$ và vỡ xương chậu phối hợp là 40,3\%

\section{SUMMARY \\ RESEARCH CLINICAL AND PARACLINICAL CHARACTERISTICS OF PATIENTS WITH \\ BLADDER RUPTURE BY TRAUMA AT VIET DUC HOSPITAL}

Objective: To study clinical and paraclinical characteristics of patients with bladder rupture due to trauma at Viet Duc hospital from January 2014 to September 2020. Methods: Descriptive cross sectional study combining retrospective and prospective on 67 bladder rupture patients undergone treatment at Viet Duc hospital. Results: The mean age of the patients was $34.5 \pm 12.8$ years old; Male patient was $82.1 \%$, female patient was $17.9 \%$. Trauma caused of traffic accident was $86.6 \%$, occupational accident was 13.4\%; The average time from the patient's accident to hospital admission was $4.08 \pm 1.34$ hours; The mean time from patient admission to diagnosis was $3.02 \pm 1.14$ hours; Traumatic shock was $37.3 \%$; X-ray results: Pelvic fracture was $11.9 \%$, intra-abdominal air was $11.9 \%$, intra-abdominal fluid was 4.5\%; Computed tomography results: Bladder wall damage was $85.1 \%$, intra-abdominal drainage was $43.3 \%$, pelvic fracture was $40.3 \%$; Combined organ damage: liver damage 